FINAL.25.7.08

6149 excl refs

\title{
A bodymind approach to psychotherapeutic groupwork with patients with medically unexplained symptoms: A review of the literature, description of approach and methodology selected for a pilot study
}

\author{
Professor Helen Payne, PhD \\ University of Hertfordshire, \\ School of Social, Community and Health Studies, Meridian House \\ 32 The Common, Hatfield, Herts \\ 01707285861 \\ h.1.payne@herts.ac.uk \\ Biography
}

Professor Helen Payne, PhD; UKCP accredited psychotherapist; Fellow of, and Senior Registered movement psychotherapist with, ADMT.UK and group analyst. Research has been concerned with DMT with young offenders;

DMT in special education; personal development groups for trainees in the psychological therapies and authentic movement groups with patients suffering moderate anxiety and depression in primary care. She has a number of publications including Creative movement and dance in groupwork; Dance Movement Therapy: Theory and practice; A handbook of inquiry in the arts therapies; DMT: Theory, research and practice; and DMT Supervision (in process). She is editor-in-chief for the new international journal Body, movement and dance in psychotherapy published by Taylor and Francis. Her clinical work influenced her approach to DMT and Authentic Movement both of which are also informed by her extensive research. She trained in Laban Dance, Person-Centered Counselling and Group Analysis and has been developing her own form of Authentic Movement with groups and individuals for 25

years. 00441438833440 


\title{
A bodymind approach to psychotherapeutic groupwork with patients with medically unexplained symptoms: A review of the literature, description of approach and methodology selected for a pilot study
}

\begin{abstract}
This paper presents a literature review of research into interventions with people with medically unexplained symptoms (MUS). The review forms the basis for the research questions, provides a rationale for an innovative approach to intervention for patients with anxiety/depression with MUS and describes the most suitable methodology for its study. An overview of the problem is provided as backdrop to the rationale. Patients with MUS make up a substantial percentage of all Primary Care (PC) consultations, are notoriously difficult to treat and make huge demands on resources. A pilot study took place in the National Health Service (NHS) in the UK between 2004 and 2007 receiving full NHS ethical approval for delivery in PC. Following on from the systematic search of the literature the argument for, and description of, the bodymind (BMA) approach to group psychotherapy (based on the discipline Authentic Movement from within the field of dance movement psychotherapy) is presented. The intervention emphasizes a verbal and non verbal integrated approach which encourages an awareness of the inter-relationship between body, self and mind. It encourages meditative, mindful movement deriving from natural body gestures and posture, relaxation, massage and promotes change in beliefs towards greater understanding of the meaning of the symptoms within a self managing framework. It is founded on the principle that bodily experience can be an avenue for meaning-making in personal development leading to increased wellbeing; better coping strategies; changes in perception of the body-felt sense and improved lifestyle choices and behaviours. The symptom is seen as a
\end{abstract}


metaphor for connections between body, self and mind. The research sought to answer a number of questions concerning the intervention such as benefits, process and outcomes from the perspective of participants and the facilitator. In order to facilitate findings to these questions the methodology selected was mixed, using both qualitative (analysis of pre, post and follow up interviews with participants and facilitator's process recordings of group sessions); and quantitative - whereby two outcome measures were completed by patients pre, during, post intervention and at follow up. Levels of medication and frequency of visits to their general practitioner (GP) were also quantified pre and post intervention and at follow up.

Key words: literature review, dance movement psychotherapy groups, authentic movement, bodymind, anxiety/depression, primary care, medically unexplained symptoms

\section{Introduction: Nature of the Problem}

Hague (2005a and b), a GP, discusses the importance of GPs and other health professionals recognising that mental health 'influences physical disease: that the two are intimately related' (ibid: 6). He goes on to claim that $30-40 \%$ of all GP work is consulting about various common mental health problems, and major studies suggest that $50 \%$ of patients with these problems present only physical symptoms to their GPs often due to the stigma of having a mental health problem. The patient is left to unravel the complexity between mental and physical health.

Patients with MUS are therefore highly prevalent in PC and present a common problem across all areas of medicine with high associated expenditure of health resource funding (Arnold at al. 2006; Fink et al. 1999,) including secondary care examinations and screening. 
MUS such as chronic somatoform pain are now understood as maladaptive responses involving physical, psychological, social and emotional factors. Psychological factors such as distraction, relaxation, fear, depression, former pain experiences and family and cultural influences modulate the way pain is experienced. It is important for GPs and other health professionals to recognise that mental health influences physical disease and that the two are intimately related or we perpetuate the body-mind Cartesian split still prevalent in this field (i.e. we have mental health services and physical health services separately funded and administered). A physical illness/injury can have accompanying psychological symptoms and a psychological stress/disorder can have accompanying physical symptoms. However, the boundaries of psychological and physiological illness are not always clearly defined and whereas this opens up many possibilities, it also makes treatment difficult.

Smith et al. (2003) recommends that treatment must focus on cause and effects of symptoms on the person's life and general well being, and that management must be multi-dimensional, addressing all aspects of the patient's life. In clinical practice, most patients with MUS are diagnosed as suffering from somatoform disorder (ICD10, F45). An evidence-based approach at the primary care (PC)-community care interface is in its infancy. Further research into integrative treatment and prevention of MUS is required.

The approach used as the intervention for this patient population, termed 'BodyMind', derives from movement psychotherapy (MP), also known in the UK as dance movement therapy (DMT) or more recently as dance movement psychotherapy (DMP), soon to become a NHS state regulated profession with the Health Professions Council (HPC). DMT has been used 
successfully for the treatment of patients with psychosomatic disorders in a treatment and evaluation project in Sweden (Thulin 1997). However, to the author's knowledge, there is no other research using the approach with people with MUS. The study aimed to investigate a group approach using an adaptation of Authentic Movement from within DMT (Adler 2002; Bernstein 1983; Chodorow 1991; Pallero 1999, 2006; Payne 2006a; Whitehouse 1979) specifically for people diagnosed as suffering from mild to moderate anxiety/depression with an accompanying MUS manifested in a bodily symptom.

\section{The Literature Review}

\section{Psychosomatic medicine and philosophical issues}

There are numerous publications on issues that may arise when working with clients with MUS/psychosomatic problems such as the experience and meaning of illness/wellness (Bullington 1999; Cassell 1991; Charmaz 1995; Fahrenberg 1986; Honkasalo 1998; Honkasalo 2000; Morse 1997; Schore 1994; Thomas 2000) and the communication of the illness experience (Broom 1997; Frank 1995; Frank 1997; Hyden 1997; Poirier 1994; Soederberg and Nordberg 199 ).

There is also a vast amount of literature questioning and challenging our beliefs and perceptions of psyche/soma in relation to the social environment (Bullington 1999; Csordas 1994; Ogden 1998; Schore 1994; ). These writings seem not only relevant to the working with those with MUS but also to the DMT field as a whole. For example, ease and dys-ease of the psyche and soma in DMT work (Bullington 2003, Parvia 2003; Thulin 1997); narratives through embodying 
emotion to motion (Berrol 1992) and the social and cultural considerations of pain and suffering for individuals (Bullington 1999; Cassell 1991; Charmaz 1995; Csordas 1994; Honkasalo 1998; Honkasalo 2000; Poirier 1994).

\section{Dance movement therapy/psychotherapy}

The foundation of DMT/P lies within the premise of the unity of body and mind (Berrol 1992; Stanton-Jones 1992). Similar discussions on this inter-relationship of the body with the mind are in the centre of the literature on psychosomatic 'dys-ease' (Bullington, 1999; Cassell, 1999; Charmaz, 1995; Csordas, 1994; Honkasalo, 1998; Honkasalo, 2000; Williams and Bendelow, 1998)

DMT has been used successfully as a complementary therapy with a wide range of populations ranging from children and adults with severe learning, emotional, social and physical disabilities to people with mental health problems, emotional and behavioural difficulties. It has also been used with patients with pain and other physical symptoms from the spectrum of psychosomatic disorders/MUS as well as organic causes, such as cancer (Dibbell-Hope) 1989, to improve wellbeing and adaptation. Goodill (2005) gives an overview of DMT in the medical environment including working with patients with conditions such as heart disease, chronic pain and HIV/AIDS. It has been applied with 'medically ill children' as illustrated by Goodill and Morningstar (1993) and by Mendelsohn (2002).

The writings on DMT and psychosomatic symptoms describe, with case illustrations, the clients' journey through the therapeutic encounter when struggling to come in terms with physical 
symptoms of an unknown medical cause (Hoer 1988; Horwitz et al 2003; Silberman-Deihl and Komisaruk, 1985; Thulin, 1997). Another article by Bullington et al (2003) uses therapists' narratives to gain understanding on the experiential aspects of pain and illness. These articles suggest outcomes such as a decrease in bodily symptoms, anxiety and use of medication; increases in psychological insight and an improvement in the perception of the symptom in the healing process. This knowledge can deepen our understanding of MUS when working with clients with somatic complaints.

An early UK pilot study using movement therapy as a support with patients from PC with medically unexplained pain (Chrysou, 1999) - a different but closely related population in that all are typically hard to reach, and seen as 'revolving door' patients. Instead of one group of 6, as in Chrysou, in this study there were 4 groups of 4-7 participants with varying ailments in each group. The shorter duration of the intervention (12 sessions as opposed to 27 in Chrysou) and the fact that there were more participants make it more cost effective.

\section{Other arts therapies}

Of relevance to DMT and MUS is other arts therapies (art, music, drama) research in this topic area. The advantages of creative, non-verbal therapies for this population are further discussed in these forms of therapy which can be seen as offering some specific benefits over verbal therapies, as the clients have, indirectly, the opportunity to process distressing feelings, thoughts and pain in a less threatening way (Becker, 1977; Bullington et al 2003; Grossman, 1992;). Clinical examples are given to illustrate the therapeutic process in music therapy (Fagen, and Wool, 1999; Magill-Levreault, 1993; O'Callaghan, 1996) and art therapy (Grossman, 1992; 
Theorell et al 1998). A research study by Standley (1992) incorporated quantitative methods to study the effects of music therapy (music listening) on anxiety and nausea during chemotherapy treatment. Both patients and nurses commented on the benefits of music also reflected in the physiological measures during and after chemotherapy. Brown et al (1989) explores pain relief through music therapy.

\section{The psychological therapies}

Psychology and verbal therapies offer extensive reading on psychosomatic/MUS theory and research. They appear from within the breadth of the psychological therapies: cognitive behavioural therapy (CBT), counselling and psychotherapy have been differentiated for their use with this patient group. CBT studies are normally conducted from a quantitative research perspective. A meta-analysis of CBT with psychosomatic clients yielded encouraging results as $71 \%$ of studies found positive improvements in reports of physical symptoms (Kroenke and Swindle, 2000). The research findings are quantifiable although they utilise subjective, patient self-reports in measuring emotional, psychosocial and physiological factors of psychosomatic illness. The results indicated the benefits of CBT including a) a decrease in anxiety, b) a decrease in depression, c) a reduction of bodily complaints, and d) increased insight (Ehlert, Wagner and Lupke, 1999). Speckens et al's (1995) study illustrated decrease in back pain in three treatment groups (CBT, relaxation training and combination of the two) as compared to controls. Lidbeck's (1997) research on group short term CBT showed a moderate improvement in perception of illness, somatic preoccupation, hypochondriasis and use of medication. However, in a recent study by Sumathipala et al. (2008) in a randomised controlled trial which evaluated CBT and compared it with structured care given by GPs it was concluded that CBT was no more efficacious than structured care over the longer term. 
Counselling (Sanders 1996) and psychoanalytic approaches (Becker 1977; Braunschweig 1998;

Erskine \& Judd 1994; Grabhorn 1998; Hadhazy et al 2000; Kuechenhoff 1998; Scoppola 1996; Milch 1998; Mueller-McDougall 1992; Nordberg et al 2001; Totton 1998; Turp 2001) rely more on phenomenological study and discussion applying theories in practice with clients presenting with psychosomatic issues. In group analysis a study by Grabhorn (1998) offers an alternative way of observing the process of group therapy with clients with psychosomatic illness. He used semantic content analysis of therapy sessions to analyse changes in the group's interaction. The group seems to have helped the clients to mobilise the expression of anxiety and aggression.

\section{Body psychotherapy}

Pertinent to a non verbal approach emphasising the body as expresser, such as DMT, is that of body psychotherapy. Several authors such as Aposhyan; (2004); Marlock and Weiss (2005);

Rothschild (2000); Shaw, (2003); Soth, (2002); Staunton, (2002); and Totton (1998, 2003 and 2005); have commented on the advantages of this approach for patients with MUS/psychosomatic conditions. Particularly, a number of authors draw on a long tradition of research (Shaw 2003) and theory (Mathew 1998; Soth 2002; Staunton 2002) on the body in psychotherapy to discuss the transferential and countertansferential issues in the therapeutic relationship. In the only randomised controlled study (Nickel et al 2006) found bioenergetics (one technique in body psychotherapy) reduced the somatisation of symptoms experienced by Turkish immigrant men.

\section{Complementary therapies}


Complementary approaches to medicine offer a wide variety of treatments, some of which have been researched in respect to efficacy of treating somatic complaints. It appears that several approaches can contribute to the well being of people who are feeling unwell: meditation (Bonadonna 2003), meditation's impact on chronic illness (Jin 1992; Majumdar et al 2002), massage (Browlee \& Dattilo 2002), tai chi (Jin 1992; Taggart et al 2003) and hypnosis (Williamson 2002).

\section{Multiple approaches}

Research into mixed approaches seems to indicate that there is unlikely to be a single intervention that offers outcomes above and beyond other forms of therapy or treatment (Creamer 1999; Hadhazy et al 2000; Jin 1992). For example a review of body-mind therapies (including relaxation exercises, meditation, hypnosis, guided imagery, biofeedback, autogenic training) in the treatment of fibromyalgia concluded that these therapies should not be favoured over other forms of therapy (Hadhazy et al 2000). The combination of different therapies according to the individual's needs and interests may be most helpful (Creamer 1999).

\section{Summary of review of literature}

The literature review revealed that psychosomatic problems/MUS have captivated the interest of many researchers, writers and clinicians. The boundaries of psychological and physiological illness are undefined. This opens up many possibilities but also makes treatment difficult. Research suggest that verbal (Bleichhardt, Timmer and Rief, 2004; Creamer, 1999; Ehlert, Wagner and Lupke, 1999; Grabhorn, 1998; Greene and Blanchard, 1994; Hadhazy et al 2000; Harrison et al 1997; Kashner et al 1995; Kroenke and Swindle 2000; Kuechenhoff, 1998; 
Lidbeck, 2003; Mayou et al 1997; Milch, 1998; Morley et al 1999; Speckens et al 1995;

Scoppola, 1996; Temple et al 1996; Turner and Jensen 1993; Warwick et al 1996), non-verbal (Brown et al 1989; Bullington et al 2003; Fagen \& Wool 1999; Grossman, 1992; MagillLevreault, 1993; O'Callaghan, 1996; Standley 1992; Theorell et al 1998) and body-orientated therapies (Bonadonna, 2003; Becker, 1977; Browlee and Dattilo 2002; Bullington et al 2003; Creamer, 1999; Hadhazy et al 2000; Jin, 1992; Keel et al 1998; Mueller-Braunschweig, 1998; Majumdar et al 2002; Nickel et al 2006; Taggart et al 2003; Thulin, 1997) can relieve MUS in many cases. One approach should not be favoured over another however.

Therefore both verbal (such as CBT, group psychotherapy and hypnotherapy) and non-verbal (such as body-orientated and body psychotherapy; DMT, art and music therapies and meditation) approaches are as beneficial as mixed approaches. The advantages of creative, non-verbal therapies can be seen as offering some specific benefits over verbal therapies as the clients have the opportunity to process distressing feelings, thoughts and bodily pain in a less direct, overt way.

However, it can be argued DMT may have an implicit advantage of solely verbal, non verbal and body orientated approaches since it can integrate all of these as in the mixed approaches. By approaching 'dys-ease' from the unity of the bodymind perspective it emphasises the body and non-verbal aspects (Becker, 1977; Bullington et al 2003;;Silberman-Deihl and Komisaruk, 1985) whilst honouring cognitive understanding and verbal modes of expression.

The following research questions arose from the literature review: 
1. Does an integrated approach binding together both verbal and non verbal approaches to MUS provide a platform for change in patient perception of symptoms?

2. What are these patients' experiences of a medium-term, group bodymind approach (BMA)?

3. What are patients' views on the benefits/outcomes in relation to coping strategies for symptoms; self managed care and self responsibility for health?

4. What are the longer-term benefits for patients attending the programme (in terms of symptom distress; re-referral rates; wellbeing; levels of anxiety/depression; frequency of GP appointments; prescription/medication rates)?

\section{The approach and how it was implemented}

Therefore for this population it was decided to use a group approach which valued the combination of verbal and the non verbal in relation to the individual's needs i.e. verbal reflection/story telling (witnessing) and personal spontaneous movement as a symbolic process (moving with the particular symptom in mind). The movement expressed as body language arises from within and feelings and thoughts integrated in an imaginative/creative framework. Consequently, in order to give potential participants the message sessions were concerned with personal learning (such as making connections between body and mind; self managing their health and wellbeing and developing better coping strategies for 'dy-ease') through both verbal and non verbal avenues, the sessions were termed 'Learning groups - a bodymind approach'. In essence this approach is embodied learning so terminology used reflected this. It removed the stigma often associated with the terms 'psychotherapy/therapy/psychological therapies' and provided ease of access to this population who otherwise may not seek out psychological therapies when labelled as such. There can be a fear of being labelled 'mad' and that their 
symptom is seen as 'all in the mind' when it is clearly experienced in the body. Mental health needs are seen by society as unacceptable when compared with physical health needs.

In addition, a group approach, over a relatively short duration, can be potentially more efficient than other current individual interventions available to this patient population such as CBT/counselling.

It has been argued elsewhere the physical and psychological benefits of an intervention such as DMT which uses physicality, the moving bodymind - as in moving the body with mindfulness for patients with psychosomatic symptoms;

'there are valid physiological reasons for the place of dance-exercise in [psychological] therapy, emphasizing the unique contribution DMT has to make in, for example the treatment of stress and psychosomatic conditions' (Payne 1992:6).

DMT/P, is a hybrid, although not dance exercise per se, it uses non stylised natural bodily movement together with verbal language in its therapeutic process - a mixing of the verbal with the non verbal whereby the right and left brain are connected. The emphasis here is on the connectivity and somatic attunement or resonance between feelings, thoughts, beliefs, symbolic non-verbal and imaginative aspects of the psychotherapeutic process. As an integrated approach for this population, it is unlike other distinct approaches which are solely either bodily symptom or psychologically focussed. It is different in that it is integrating body and psychological aspects, concentrating and working with, and through, the distress/dys-ease of the symptom rather than trying to distract from, or eradicate it which can lead to further disassociation from the body. 
The intervention explored physical symptomatology through symbolic movement using aspects of Authentic Movement (Whitehouse 1979; Bernstein 1983; Chodorow 1991; Adler 2002;

Pallero 2003, 2006; Payne 2006a). The central element is mindfulness as the body is moved or 'being moved' with the symptom in mind. The therapeutic goals included:

1. Promoting change in perception of bodily symptoms;

2. Increasing levels of self understanding (for example, making links between lifestyle, stress and symptoms);

3. Increasing a sense of wellbeing;

4. Raising levels of body awareness (bodily intelligence);

5. Facilitating group members' capacity to self-heal with a focus on self management rather than over-reliance on GP visits, medical cures and/or dependency on medication (the latter of which most sufferers would prefer not to take at all);

6. Promoting group cohesion.

The specific way the intervention was conducted depended to some extent on the assessment made by the facilitator, her own thoughts and creative approach to the population, the group dynamics and needs, and the facilitator's reflections from weekly supervision with a practitioner (also experienced in this work). The author, as the principal investigator, met the facilitator every fortnight for debriefing to ensure the practice methodology being used was appropriate to the research needs. The facilitator was an experienced health practitioner, HPC registered, trained in physiotherapy and at post graduate level in DMT and had a recent, separate four year course in Authentic Movement with the principal investigator. 
Non-verbal therapy can be beneficial to transcend barriers of ability and language, for example according to Becker (1977) language can act as a defence. It is possible that this may be one of the advantages of using movement as well as words as an intervention with patients with MUS. By emphasising the non verbal (a right hemisphere specialisation) defences normally utilised may be bypassed allowing for a capacity to connect with bodily experience (and themselves) in a new way. The body provides direct access to feelings, the unconscious and the imagination in the right hemisphere which are not mediated by words and logical thought found in the left hemisphere. In this way right brain and left brain functions come together as the movement experiences are reflected upon verbally in the group.

The psychotherapeutic theory underpinning the intervention approach is integrative (i.e. behavioural, humanistic and psychoanalytical). Behavioural, since the prescribed exercises and processes are directed at a change in perception, which in turn, it is hoped, will lead to a change in behaviour.

Humanistic psychotherapy puts the patient at the centre of the therapeutic process (as the expert on the experience of their own condition). This parallels the research philosophy whereby participants are seen as people collaborating in their own process, contributing to the study as those with lived experience of a mental health issue rather than subjects of research.

Although psychodynamic interpretations might be made by the facilitator at times in offering witnessing they were stated as owned by her and taken on board, or not, by the participant. The group aspect is crucial for the supportive ethos whereby each participant can learn from each 
other and place their own lives in the context of others. The roles of witness and mover, from the discipline of Authentic Movement, in a dyad as well as in the group as a collective would not be possible without a safe group formation.

The use of mindfulness, imagery and 'Moving from within' in the language of the body, and with the symptom in mind, are all fundamental. Specific exercises were developed together with relaxation, gestalt, massage, breathing and meditation techniques, for example. All exercises were determined by participants' needs and selected from a repertoire previously tried and tested with other groups in social and health care settings. Levels of self consciousness, group trust and coherence, safety elements (Payne 2001) and so on were considered before embarking on any movement work. After two or three weeks of preparation the group was encouraged to move with eyes closed and to witness at times. Some opportunities were provided to share personal stories at the beginning of sessions.

There follows a brief overview of the intervention which falls into four phases, all with gentle transitions from one to the next. It is worth noting that phases two and three are interchangeable depending on the needs and progression of the group. Also the progression into phases three and four is generally more applicable during the later stages of the group when trust has been established.

The intervention sessions included a verbal check-in, the introduction and development of structured exercises for individual, dyad as well as group work and a verbal check out. Participants were invited to scribe in a personal journal following the movement experiences in 
each session.

Phase One: There may be a brief explanation of any psycho-educational aims outcomes from the facilitator here. The aim of this first phase is to check-in with the group and begin to emphasise the focus on bodily experience with feeling, thought and imagination.

Phase Two: The aim here is to further the embodied experience through relaxation, massage and linking the self with proprioceptive/kinaesthetic (bodily) sensations and the other senses with movement, symptoms and the imagination.

Phase Three: This phase fosters the earlier work by deepening and broadening the experience of connection between inner and outer worlds with the metaphors arising from the bodily experiences. Usually participants take the role of mover and witness in this phase. As a result an embodied realisation may be made between the self, previous emotional stresses, current lifestyle and expression of metaphors generated.

Phase Four: Here the participants are encouraged to reflect on their experiences and to share in the group verbally. Time is taken for participants to write in their journals if desired. The preparation for ending the session is made.

At the start of the group there was always time for people to arrive, settle and check in verbally. A thorough embodied warm up follows focusing on surfaces, skin, joints, muscles and ways of moving using shared leadership techniques and games. Language, music and props with 
movement to bridge into bodily focus and to keep contact are incorporated here.

In the next phase focused work takes place. Participants are invited to explore ways of learning about themselves and their symptoms. This can be through conscious learning and experiential learning, always connecting the worlds of inner and outer experience through the body, movement and the creativity of imagination. All the approaches used in the group related to the symptom and how that was experienced, managed, related to, understood and held as an experience. An example of how this phase could look would be using movement or inner journeying experiences then reflecting on these through image-making and writing. Alternatively mark-making on paper can be directly linked with the body, the senses and feelings, by, for example, participants drawing around each other's bodies and decorating their own image in relation to positions and qualities of sensation and feeling.

Group themes, feelings and dynamics were embodied symbolically in the work. For example, themes such as resistance, support and trust can be put into movement with a partner, as can how we believe we are seen, how we feel we are seen and what is actually seen by others in relation to self and the symptom. This can be done through participants adopting either the role of witness and mover as in authentic movement and having time for transition and reflection. Often these roles can be creatively weaved in as a way of entering into mindfulness experiences whereby the present moment is honoured.

There was an emphasis on creating an environment where participants could reflect and be supported in finding and valuing what they know helps and supports them already, for example 
identifying helpers/inner guides in imagery or discussing coping strategies (emotional, spiritual, social, physical). There was also a focus on finding personal resources and developing responsibility.

Breath work and relaxation is always used in phase one or two. Participants were invited to enter into body sensing and guided/own imagery in order to learn from the experience, and find some skills in monitoring and influencing states of stress and relaxation in relation to emotional wellbeing. It is helpful to graduate the transition into any internal reflection such as relaxation or guided/free form imagery. These transitions (which may remain) help honour what is manageable for an individual and helps foster self care and responsibility. This can look like, for example, participants keeping eyes open whilst focusing inward, or choosing an active, stretchrelease type, relaxation instead of having to tolerate eyes closed and stillness.

In preparation for the end, phase four, there is a time for verbal group reflection and using confidential, personal journals to record anything they wish.

\section{Selected Methodology}

Although initial studies have been promising, more research is required to establish the efficacy of interventions with this population. Previously both quantitative and qualitative methods have been employed separately to study the psychosomatic phenomenon in therapy.

Phenomenological studies have been well received in psychotherapy literature and, through case illustrations; readers can witness stories of regaining hope whilst coming to terms with 
debilitating bodily symptoms

In order to answer the above research questions this study creatively combines aspects from two approaches, qualitative and quantitative. Qualitative to add depth, validity and relevance derived from the subjective experience of participants, and breadth and objectivity harvested from the validated outcome measures for the quantitative aspect. A small number of participants is desirable for such an in-depth methodology. A total of 18 out of 24 participants completed the study. This number of participants provides for 'power' statistically (for the quantitative aspect) and more breadth and possibility of internal reliability for any changes in scores on the outcome measures at pre post and follow up.

It set out to systematically evaluate the outcomes of a bodymind programme of intervention with patients suffering from anxiety/depression with at least one MUS.

The researcher is a practitioner who has specialised in the qualitative study of client perceptions of psychotherapy using dance, movement and words in various settings (Payne 1984, 1997, 1999, 2006). As a practitioner-researcher (Payne 1993) she ensured the study was applied research grounded in the practice itself. In addition, the researcher values collaboration 'with' research 'participants' as opposed to doing research 'on' research 'subjects'. These values are embedded in the research methodology.

The pluralistic (Cooper and McLeod 2007) mixed methodological approach was also adopted as it is recommended for DMT research for in-depth cross sectional studies (Berrol 2005) and does 
promote these aforementioned values. Consequently, it uses semi-structured interviews (qualitative) and validated, standardised, outcome measures (for quantitative, measurements). This methodology builds on the only other UK study by Chrysou (1999) where only qualitative data, rather than a mixed data set, was collected.

For the qualitative analysis a framework for the generation of theory grounded in data was arrived at by using a method described by Glaser and Strauss (1967) as constant comparative analysis. When applying constant comparative analysis, data is collected, coded, and compared with earlier data for the generation of categories, their properties, and the relationships occurring between them. Facilitator's process recordings were systematically raked through in a similar thematic analysis as a comparison to participant's views and outcome measures

Participants were sent their interview transcriptions to invite approval, amendments or comments. If requested they, and other collaborators, were sent a short report following the completion of study. The inquiry, therefore, embraced patient involvement as consultants as well as that of counsellors, GPs and other referrers from health professionals in PC resulting in a multi-facetted pool from which participants could be drawn.

\section{Participants}

Participants were either self referred or referred from PC by a health professional, such as counsellors, although in all cases they made the call themselves. The criteria for participation specifically included those with MUS (such as irritable bowel syndrome (IBS), depression with lethargy, stress with panic attacks, anxiety as manifested in, for example, joint pain, skin 
problems, breathing difficulties) for more than two years duration, with no known organic cause. They had to be over 18 years, not have a diagnosis of learning disability/relevant physical illness/ eating disorder, nor have been under a consultant psychiatrist within the previous 6 months nor experienced a complex trauma in the last 6 months.

Since a physical illness can have accompanying psychosomatic symptoms and the psychological stress/disorder can have an accompanying physical illness, referrals (or referrers) required a clarity about which part of the problem is thought to be psychological and why it is thought not to be a consequence of diagnosed physical illness. Therefore presentations were made to six local GP surgeries and two physiotherapy departments at local hospitals outlining the inclusion/exclusion criteria and the project as a whole. Self referring participants' GPs were not contacted unless the participant requested we informed them, most did not make this request.

\section{Procedure}

Since the research question did not require a comparison group the study utilised a comprehensive evaluation method using both qualitative and quantitative measures in a withinsubjects repeated design, triangulating the analysis from outcome measures, semi structured interview themes and facilitator's process recordings.

The participants were asked to complete the Clinical Outcome Routine Evaluation (CORE) ${ }^{\mathrm{i}}$ Questionnaire (Barkham, et al 2001) and Measure Yourself Medical Outcomes Profile $\left(_{\text {MYMOP) }}{ }^{\text {ii }}\right.$ (Evans et al 2002; Paterson 1996; ) before entering one of four groups. MYMOP is a symptom focussed, patient generated instrument for measuring outcomes. It concentrates and 
works with the symptom rather than trying to eradicate or medicate it.Participants can rate themselves in four areas on CORE: Wellbeing, b) Problems/symptoms, c) Life functioning, d) Risk. This, and MYMOP, was repeated during the group, at the end of the therapy programme and at a three month follow up. CORE enables the researchers to make comparisons to normative data collected from clinical and non-clinical populations. Because it is extensively used in PC in the UK, and results fed back to a central database, there is an added facility of being able to use this as a reference point or benchmark when interpreting data (results of the quantitative analysis are available from the author).

As well as pre-intervention and post intervention semi structured interviews to elicit symptoms distress and views on the approach, in this type of study it is also useful to include a three month follow-up interview. From this can be seen what, if any, longer-term effects of the intervention are experienced and to clarify their overall level of satisfaction with the programme, including the referral procedure. Three months is not too long to forget the experience or too short a time for the symptom/dys-ease to have returned (if it has disappeared/reduced) to the same state as that before the intervention. Participants were asked to keep a journal on their progress in the group in and between sessions. The facilitator's process notes were compared with participants' perceptions of the intervention. Analysis from these data aimed to discover the perceived experiential aspects of the process and add depth to our knowledge of bodymind connections.

\section{The Research Process}

A brief outline of what actually took place follows to give an idea of the research process the participants went through in completing the study. 
Following the initial telephone referral from the participant a screening took place over the telephone to assess suitability and inclusion/exclusion criteria were met. A flyer about the project was forwarded if they had received one from the referrer.

An appointment was made for all fulfilling the relevant criteria for an individual briefing meeting. This explained the research, assessed suitability; explained and issued informed consent forms and withdrawal procedures, together with the issue of confidentiality, and answered any questions. It was made clear from the outset that the research had gained full NHS ethical approval and all data would be anonymised and confidential, seen only by the research team. They were told they could withdraw from the research at any time without adverse consequences, for example they might choose to remain within the intervention group but retreat from the research study.

At the pre-intervention individual research interview informed consent was checked, the two outcome measures administered; a semi-structured interview conducted to elicit symptoms and current coping strategies; hopes, fears and expectations and the participant's perception of the referral procedures explored. Post intervention appointments were also agreed.

At the individual pre-intervention assessment the participant met with the facilitator who was able to assess for suitability for the group recruiting next, answer questions and explain the nature of the group, its boundaries and ground rules. 
The intervention lasted for 12 weeks ( 2 hours per week), In week 6 of the intervention the ingroup MYMOP was completed at the end of the session. This was again completed in week 13 at an individual post-intervention meeting with the facilitator where CORE was also administered once more. Here questions were answered and information about further resources for support distributed. A semi structured interview also in week 13 sought views on the process and benefits of the intervention, visits to the GP and medication usage and follow up semi-structured interviews dates agreed.

Finally, at a three month post intervention follow up a semi structured individual interview sought participants' experiences of the sessions, their symptoms and the group, number of visits to GP and medication levels. The last MYMOP and CORE were also completed.

\section{Summary}

An overview of the literature leading to a rationale for a group bodymind approach, using both verbal and non verbal means as an intervention with patients chronic (over two years) MUS has been provided. This forms the backdrop to the context for the research questions and selected methodology for an innovative study in PC aimed at examining the approach with this patient group. The bodymind intervention adopted was described in detail. Unfortunately due to word constraints it has not been possible to include the outcomes of the study in this short paper, they are available from the author however. ${ }^{\text {iii }}$

\section{Acknowledgements}

Many thanks go to participants in the study for their valuable contributions. Appreciations also to 
those members of the steering group: Sarah Webb, Head of the WelHat Counselling Service; Hannah Murdoch, the group facilitator; and Dr David Wellsted in particular for his helpful suggestions on methodology and research assistants Jeni Boyd and Sabine Fichter all of the University of Hertfordshire.

\section{References}

Adler, J. (2002) Offering from the conscious body. Vermont: Inner Traditions

Aposhyan, S. (2004). Body, mind and psychotherapy: Principles, techniques and practical application. New York: W.W. Norton \& Company.

Barkham, M., Margison, F., Leach, C., Lucock, M., Mellor-Clark, J., Evans, C., Benson, L., Connell, J., Audin, K. \& McGrath, G. (2001). Service profiling and outcomes benchmarking using the CORE-OM. Journal of Consulting and Clinical Psychology, 69, 184-196.

Bassett, D. and Pilowsky I. (1985) A study of brief psychotherapy for chronic pain. Journal of Psychosomatic Research, 29, 3, 259-254

Becker, H. (1977). A non-verbal therapeutic approach to psychosomatic disorders. Psychotherapy and Psychosomatics, 28, 1, 330-336.

Bernstein, C.F. (1980). A mythological quest: Jungian movement therapy with the 
psychosomatic client. American Journal of Dance Therapy, 3, 2.

Berrol, C. (2005) How to mix quantitative and qualitative methods in a dance movement therapy research project. In: R.F Cruz and C.F Berrol (Eds) Dance/Movement therapists in action: a working guide to research options. Springfield, IL: Charles C Thomas

Bleichhardt, G., Timmer, B. \& Rief, W. (2004). Cognitive-behavioural Therapy for patients with multiple somatoform symptoms-a randomised controlled trial in tertiary care. Journal of Psychosomatic Research, 54, 4, 449-454.

Bonadonna, R. (2003). Meditation's impact on chronic illness. Holistic Nursing Practice, 17, 6, 309-319.

Broom, B. (1997). Somatic Illness and the patient's other story. London: Free Association Books.

Browlee, S. \& Dattilo, J. (2002). Therapeutic massage as a therapeutic recreation facilitation technique. Therapeutic Recreation Journal, 36, 4, 369-381.

Brown, C.J., Chen, A.C.N. \& Dworkin, S.F. (1989). Music in the control of human pain. Music Therapy 8, 1, 47-60.

Bullington, J., Nordemar, R., Nordemar, K. \& Sjostrom-Flanagan, C. (2003). Meaning out of 
chaos: a way to understand chronic pain. Scandinavian Journal of Caring Sciences, 17, 325331.

Cassell, E. (1991) Recognising suffering. Hastings Center Report, 24-31.

Csordas, T. (Ed). (1994). Embodiment and Experience: The existential ground of culture and self. Cambridge: Cambridge University Press.

Charmaz, K. (1995) The body, identity and the self. The Sociological Quarterly; 36: 657-680.

Chodorow, J. (1991) Dance therapy and depth psychology: The moving imagination. London: Routledge

Chrysou, M. (1999) Psychosomatic aspects of pain: An exploration of physical and psychic pain in dance movement therapy. Unpublished MA dissertation, Laban Centre for Movement and Dance, London.

Clarkson, P. (1995). The Therapeutic Relationship in Psychoanalysis, Counselling Psychology and Psychotherapy. London: Whurr.

Creamer, P. (1999). Effective management of fibromyalgia: exercise, drugs and cognitive behavioral therapy are all helpful. Journal of Musculoskeletal Medicine, 16, 11, 622-624.

Cooper, M. and McLeod, J. (2007) A pluralistic framework for counselling and psychotherapy: 
Implications for research. Counselling and Psychotherapy Research, 7, 3: 135-143.

Dibbell-Hope, S. (2000) The use of dance/movement therapy in psychological adaption to breast cancer. The Arts in Psychotherapy; 27: 51-68.

Ehlert, U., Wagner, D. \& Lupke, U. (1999). Consultation-liaison in the general hospital; effects of cognitive-behavioral therapy in patients with physical nonspecific symptoms. Journal of Psychosomatic Research, 47, 5, 411-417.

Erskine, A., \& Judd, D. (Eds.). (1994). The imaginative body: Psychodynamic therapy in health care. London: Whurr.

Evans, C, Connell, J., Barkham, M., Margison, F., Mellor-Clark, J., McGrath, G. \& Audin, K. (2002). Towards a standardised brief outcome measure: Psychometric properties and utility of the CORE-OM. British Journal of Psychiatry, 180, 51-60.

Fagen, T.S. \& Wool, C.A. (1999). Conjoint therapy: Psychiatry and music therapy in the treatment of psychosomatic illness. International Journal of Arts Medicine, 6, 1, 4-9.

Fahrenberg, J. (1986). Psychophysiological Individuality: A pattern analytic approach to personality research and psychosomatic medicine. Advances in Behaviour Research and Therapy, 1-2, 43-100.

Foulkes, S.H. (1948) Introduction to Group Analytic Psychotherapy. London: Heinemann. 
Foulkes, S.H. (1964) Therapeutic group analysis. London: George Allen and Unwin Ltd.

Frank, A.W. (1995). The Wounded Storyteller: Body, Illness and Ethics. Chicago: The University of Chicago Press.

Frank, A.W. (1997). Enacting Illness Stories: When, what, and why. In H. Lindemann-Nelson (Ed). Stories and Their Limits: Narrative Approaches to bioethics. London: Routledge.

Glaser, B.G. and Strauss, A.L. (1967) The discovery of grounded theory. Chicago: Aldine.

Goodill, S.W. \& Morningstar, D.M. (1993) The role of dance/movement therapy with medically involved children. International Journal of Arts Medicine; 2:24-7.

Grabhorn, R. (1998). Affective experience in a case of group therapy with psychosomatic patients. Psychoanalytic Inquiry, 18, 3, 490-511.

Greene, B., \& Blanchard, E. B. (1994). Cognitive therapy for irritable bowel syndrome. Journal of Consulting \& Clinical Psychology, 6, 576-82.

Grossman, G. (1992). Psychosomatic illness treated by group therapy and group art therapy. Canadian Art Therapy Journal, 6, 2, 36-55.

Hadhazy, V.A., Ezzo, J., Creamer, P. \& Berman, B.M. (2000). Mind-body therapies for the treatment of Fibromyalgia: A systematic review. Journal of Rheumatology, 27, 2911-2918. 
Hague, J (2005a) Primary cares. Healthcare Counselling and Psychotherapy Journal, 5, 4, 31.

Hague, J. (2005b) Releasing the millions. www.icn.csip.org.uk/download accessed 5.5.08

Harrison, S., Watson, M. \& Feinmann, C. (1997). Does short-term group therapy effect unexplained medical symptoms? Journal of Psychosomatic Research, 43, 4, 399-404.

Hoer, C. (1988) A description of a dance therapy intervention focussing on the therapeutic relationship: describing the individual therapy of an eight year old boy with psychosomatic diagnosis. Unpublished Master’s dissertation, Langen Institute, Monheim, Germany.

Honkasalo, M. (1998). Space and embodied experience: Rethinking the body in pain. Body $\&$ Society, 4, 2, 35-57.

Honkasalo, M. (2000). Chronic pain as a posture towards the world. Scandinavian Journal of Psychology, 41, 197-208.

Hyden, L. (1997). Illness and narrative. Sociology of Health \& Illness, 19, 1, 48-69.

Jin, P. (1992). Efficacy of Tai Chi, brisk walking, meditation, and reading in reducing mental and emotional stress. Journal of Psychosomatic Research, 36, 361-370.

Kashner, T. M., Rostk Cohen, B., Anderson, M., \& Smith, G. R., Jr. (1995). Enhancing the health of somatization disorder patients. Effectiveness of short-term group therapy. 
Psychosomatics, 36, 462-470.

Keel, P.J., Bodoky, C., Gerhard, U. \& Muller, W. (1998). Comparison of integrated group therapy and group relaxation training for fibromyalgia. Clinical Journal of Pain, 14, 232-238.

Kroenke, K., \& Swindle, R. (2000). Cognitive-behavioral therapy for somatization and symptom syndromes: a critical review of controlled clinical trials. Psychotherapy and Psychosomatics, 69, 205-215.

Kuechenhoff, J. (1998). The body and the ego boundaries: A case study on psychoanalytic therapy with psychosomatic patients. Psychoanalytic Inquiry, 18, 3, 368-382.

Lidbeck, J. (2003). Group therapy for somatization disorders in primary care: Maintenance of treatment goals of short cognitive-behavioural treatment one-and-a-half-year follow-up. Acta Psychiatrica Scandinavica, 107, 6, 449-456.

Magill-Levreault, L. (1993). Music therapy in pain and symptom management. Journal of Palliative Care, 9, 42-48.

Majumdar, M., Grossman, P., Dietz-Waschkowski, B. Kersig, S. \& Walach, H. (2002). Does mindfulness meditation contribute to health? Outcome evaluation of a German sample. Journal of Alternative and Complementary Medicine, 8, 6, 719-730. 
Marlock, G. \& Weiss, H. (Eds). (2005) Handbuch der Koerperpsychotherapie. Goettingen: Hogrefe Verlag.

Mathew, M. (1998) The body as instrument. Journal of British Association of Psychotherapy, 35, 17-35.

Mayou, R.A., Bryant, B.M. Sanders, D., Bass, C., Klimes, I.\& Forfar,C. (1997). A controlled trial of cognitive behavioural therapy for non-cardiac chest pain. Psychological Medicine, 27 (5), 1021-1031.

McDougall, J. (1992). Theatres of the body: A psychoanalytical approach to psychosomatic illness. London: Free Association Books.

Mendelsohn, J. (2004) Dance/Movement Therapy with Hospitalized Children. American Journal of Dance Therapy; 21: 65-80.

Milch, M.E. (1998). Psychotherapy with severely disturbed psychosomatic patients with hypertension. Psychoanalytic Inquiry, 18, 3, 445-468.

Morley, S., Eccleston, C., \& Williams, A. (1999). Systematic review and meta-analysis of randomised controlled trials of cognitive behaviour therapy and behaviour therapy for chronic pain in adults, excluding headache. Pain, 80, 1-13.

Morse, J.M. (1997). Responding to threats to integrity of self. Advances in Nursing Practice, 19, 4, 21-36. 
Mueller-Braunschweig, H. (1998). The effects of body-related psychotherapy in psychosomatic illnesses. Psychoanalytic Inquiry, 18, 3, 424-444.

Nickel, M; Cangoeza, B; Bachlerc,E; Muehlbacher M, Lojewski N, Mueller-Rabea,N; Mitterlehnera FO, Egger C;, Leiberich P; Rother,N Buschmann W; Kettlera C, Gild FP;LLahmanne,C; Fartacek R;, Rothera,WK; Loewe, TH;Nickel C (2006) Bioenergetic exercises in inpatient treatment of Turkish immigrants with chronic somatoform disorders: A randomized, controlled study. Journal of Psychosomatic Research 61, 507-513

Nitson, M. (1996) The anti group. London: Routledge.

Nordberg, A., Bergsten, M. \& Lundman, B. (2001). A Model of Consolation. Nursing Ethics, 8, 6, 544-553.

O'Callaghan, C.C. (1996). Pain, music creativity, and music therapy in palliative care. Complementary Medicine International, 3, 2, 43-48.

Ogden, J. (1998). Health Psychology: A textbook. Buckingham: Open University Press.

Pallero, P. (Ed) (1999) Authentic movement: essays by Mary Starkes Whitehouse, Janet Adler and Joan Chodorow Vol 1. London: Jessica Kingsley. 
Pallero, P. (Ed) (2006) Authentic movement. Vol. 2. London: Jessica Kingsley

Parvia, R. (2003). What can Dance Movement Therapy do for fibromyalgia? E-motion, 14, 4, 8-

9.

Paterson C. (1996) Measuring outcomes in primary care: a patient generated measure, MYMOP, compared with the SF-36 health survey. British Medical Journal, 20; 312 (7037):1016-20.

Payne, H. (1987) Adolescents' perceptions of movement therapy. Unpublished MPhil thesis, University of Manchester.

Payne, H. (1997) The experience of a dance movement therapy programme in training. Unpublished $\mathrm{PhD}$ thesis, University of London.

Payne, H. (1999) A dance movement therapy group with young offenders. In: C Schaeffer (Ed) Innovative interventions in child and adolescent psychotherapy. New York: John Wiley.

Payne, H. (1992) Introduction to Dance Movement Therapy. In: H Payne (1992) (ed) Dance movement therapy: theory and practice. London and New York: Routledge

Payne, H.L. (1993) The practitioner-researcher. In: HL Payne (ed) A handbook of inquiry in the arts therapies. London: Jessica Kingsley. 
Payne, H. (2001) Student experiences in a personal development group: the question of safety. European Journal of Psychotherapy, Counselling and Health, 4, 2,267-292

Payne, H.L. (2006a) The body as container and expresser: Authentic Movement groups in the development of wellbeing in our bodymindspirit. In: J Corrigall; HL Payne and H Wilkinson (Eds) About a body: Working with the embodied mind in psychotherapy. London: Routledge.

Payne, H.L. (2006b) The lived experience of students in a dance movement therapy group: loss, physical contact and the approach. In: HL Payne (Ed) Dance movement therapy: Theory, research and practice. London and New York: Routledge.

Poirer, D. (1994). Expressing Illness. Medical Humanities Review, 10, 1, 74-79.

Rooijmans,H. (1995). Cognitive behavioural therapy for medically unexplained physical symptoms: a randomised controlled trial. British Medical Journal, 311, 1328-1332.

Rothschild, B. (2000) The Psychophysiology of Trauma and Trauma Treatment. New York, NY: W.W. Norton \&Co.

Ruddy, R. \& House, A. (2005). Meta-review of high-quality systematic reviews of interventions in key areas of liaison psychiatry. The British Journal of Psychiatry, 187, 109-120. 
Sanders, D. (1996) Counselling for Psychosomatic Problems. London: SAGE Publications.

Schore, A.N. (1994). Affect Regulation and the Origin of the Self: The Neurobiology of

Emotional Development. New Jersey: Lawrence Erlbaum Associates, Inc.

Scoppola, L. (1996). Group processes and psychosomatic phenomena. Group Analysis, 29, 4, 427-439.

Shaw, R. (2003). The embodied Psychotherapist: The therapist's body story. Hove: BrunnerRoutledge.

Silberman-Deihl, L. \& Komisaruk, B.R. (1985). Treating psychogenic somatic disorders through body metaphor. American Journal of Dance Therapy, 8, 37-45.

Smith, R.C., Lein, C., Collins, C., Lyles, J.S., Given, B., Dwamena, F.C., Coffey, J., Hodges, A.M., Gardiner, J.C., Goddeeris, J., Given, C.W. (2003). Treating patients with medically unexplained symptoms in primary care. Journal of General Internal Medicine, 18, 6, 478-489.

Soederberg, S. \& Nordberg, A. (1995). Metaphorical pain language among fibromyalgia patients. Scandinavian Journal of Caring Sciences, 9, 55-59.

Soth, M. (2002). A response to Maggie Turp's paper from a body psychotherapy perspective. European Journal of Psychotherapy, Counselling \& Health, 5, 2, 121-133. 
Speckens, A.E., Van Hemert, A.M., Spinhoven, P., Hawton, K.E. Bolk, J.R., Rooijmans, H. (1995). Cognitive behavioural therapy for medically unexplained physical symptoms: a randomised controlled trial. British Medical Journal, 311, 1328-1332.

Standley, J. (1992). Clinical applications of music and chemotherapy: The effects on nausea and emesis. Music Therapy Perspectives, 10, 1, 27-35.

Staunton, T (Ed.) (2002). Body Psychotherapy. Hove: Brunner-Routledge

Sumathipala, A., Siribaddana, S., Abeysingha, M.R.N., de Silva, P., Dewey, M., Prince, M., Mann, A.H. (2008). Cognitive-behaviour therapy v. structured care for medically unexplained symprtoms: randomised controlled trial. The British Journal of Psychiatry; 193: 51-59.

Taggart, H.M., Arslanian, C.L., Bae, S. \& Singh, K. (2003). Effects of Tai Chi exercise on fibromyalgia symptoms and health-related quality of life. Orthopaedic Nursing, 22, 5, 353-360.

Temple, N., Walker, J. \& Evans, M. (1996). Group psychotherapy with psychosomatic and somatising patients in a general hospital. Psychoanalytic Psychotherapy, 10, 3, 251-268.

Theorell, T., Konarski, K., Westerlund, H. Burell, A.M., Engstroem, R., Lagercrantz, A.M., Teszary, J. \& Thulin, K. (1998). Treatment of patients with chronic somatic symptoms by means of art psychotherapy: A process description. Psychotherapy and Psychosomatics, 67, 1, 50-56. 
Thomas, S. (2000). A phenomenologic study of chronic pain. Western Journal of Nursing Research, 22, 6. 683-705.

Thulin, K. (1997). When words are not enough: Dance therapy as a method of treatment for patients with psychosomatic disorders. American Journal of Dance Therapy, 19, 1, 25-43.

Totton, N. (1998). The Water in the Glass: Body and mind in psychoanalysis. London: Rebus Press.

Totton, N. (2003) Body psychotherapy: An introduction. Milton Keynes: Open University Press.

Totton, N. (Ed) (2005). New dimensions in body psychotherapy. Milton Keynes: Open University Press.

Turner, J. A., \& Jensen, M. P. (1993). Efficacy of cognitive therapy for chronic low back pain. Pain, 52,169-177.

Turp, M. (1999). Working with body storylines. Psychodynamic Counselling, 5, 3, 301-317.

Turp, M. (2001). Psychosomatic Health: The body and the word. Basingstoke: Palgrave.

Warwick, H.M., Clark, D.M., Cobb, A.M. \& Salkovskis, P.M. (1996). A controlled trial of cognitive-behavioural treatment of hypochondriasis. British Journal of Psychiatry, 169, 2, 189- 
195.

Whitehouse, M (1979) C.G. Jung and Dance Therapy: Two major Principles. In: P. Bernstein (Ed.) Eight Theoretical Approaches in Dance/ movement Therapy. Dubuque: Kendall/Hunt Publishing Company.

Williams, S.J. \& Bendelow, G. (1998) The Lived Body: Sociological Themes, Embodied

Issues. London: Routledge.

Yalom, I (1970) The Theory and Practice of Group Psychotherapy. New York: Basic Books.

\section{ENDNOTES}

' Clinical Outcomes Routine Evaluation (CORE) is the first standardised public-domain approach to audit, evaluation and outcome measurement for UK psychological therapy and counselling services. It was developed by the Psychological Therapies Research Centre, University of Leeds which co-ordinated it from 1995-1998 through a multi-disciplinary team of researchers and practitioners representing the major psychological therapy professions. http://www.coreims.co.uk accessed 7.10.04

ii Measure Yourself Medical Outcomes Profile (MYMOP) is a patient generated instrument for measuring outcomes developed by the Department of Social Medicine, University of Bristol and evaluated in NHS and complementary health care settings. http://www.coreims.co.uk/outcomecore.htm accessed 7/10/04.

iii Outcomes from the study are reported in separate linked papers. 